\title{
Sistem Informasi Geografis Pariwisata Kabupaten Karo Menggunakan Google Maps Berbasis Web
}

\author{
${ }^{1)}$ Henra Munthe \\ UNIKA ST. Thomas SU, Jl. Setiabudi No 479 F Tanjungsari, Medan, Sumatera Utara, Indonesia \\ Email : henra631@gmail.com \\ ${ }^{2)}$ Sorang Pakpahan \\ UNIKA ST. Thomas SU, Jl. Setiabudi No 479 F Tanjungsari, Medan, Sumatera Utara, Indonesia \\ Email : sorangpakpahan2701@gmail.com
}

\begin{abstract}
Karo Regency is one of the areas in North Sumatra Province that has the potential to become a tourism area, with the Vision "Realizing Karo Tourism that is advanced, Modern environmentally friendly and highly competitive by maintaining karo cultural values through the broadest participation of the community and business world to increase Regional Original Revenue "The Karo District Government has promoted through mass media such as newspapers, pamphlets, distributing brochures and promoting through blogs. However, this method is not enough to inform tourism extensively towards domestic tourists and foreign tourists. The design and manufacture of Geographic Information Systems (GIS) Tourism is expected to be able to display tourist maps of Karo Regency in the form of a degital map, which can be accessed by tourists. In the Design of Web-Based Karo Tourism Geographic Information System carried out by collecting data, observing and interviewing the Secretary of the Office at the Karo District Tourism and Culture Office and designing tourism maps displayed in this system using Google Maps, the software used in building this application is PHP (Personal Home Page) as a programming language, MySQL as a database server, Macromedia Dreamweaver 8 as the Design Editor. Karo Regency's geographic tourism information system is a system that provides information to tourists about the location of tourist attractions and tourism support facilities in Karo District.
\end{abstract}

Kata Kunci : Sistem Informasi Geografis, Google Maps, Pariwisata.

\section{PENDAHULUAN}

Kabupaten Karo merupakan salah satu daerah andalan sektor kepariwisataan di Sumatra Utara yang memiliki potensi tidak kalah dengan wisata lainnya di Indonesia. Potensi kepariwisataan dapat berkembang dan dapat dijadikan sebagai produk andalan yang layak dijual di pasar global karena memiliki beraneka ragam objek wisata baik jenis, bentuk, maupun ciri keunikan dari tempat wisata masing-masing. Sektor wisata yang beragam dengan keunikannya dan didukung dengan fasilitas serta sarana transportasi yang tersedia di kawasan wisata dapat memberikan pendapatan daerah yang sangat besar.

Pemerintah Kabupaten Karo telah melakukan promosi melalui media masa seperti surat kabar dan pamflet. Namun metode tersebut belum cukup menginformasikan kepariwisataan secara meluas kepada wisatawan Lokal maupun Asing. Para wisatawan akan mengalami kesulitan untuk menentukan perencanaan perjalanan wisata karena gambaran daerah wisata tersebut tidak tersedia seperti visualisasi tempat, jarak antar daerah wisata serta jalan yang akan dilalui. Adapun pembuatan sistem informasi geografis pariwisata diharapkan dapat menampilkan gambaran peta wisata Kabupaten Karo sehingga lebih menarik dan dapat dinikmati oleh parawisatan. Penyajian informasi dalam bentuk web akan memudahkan wisatawan untuk mengakses Informasi dan lokasi tempat wisata. Teknologi Sistem Informasi Geografis (SIG) telah berkembang pesat yang dimana SIG dibuat dengan menggunakan informasi yang berasal dari pengolahan sejumlah data, yaitu data geografis atau data yang berkaitan dengan posisi obyek di permukaan bumi.

Teknologi SIG mengintegrasikan operasi pengolahan data berbasis database yang biasa digunakan saat ini, seperti pengambilan visualisasi yang khas serta berbagai keuntungan yang mampu ditawarkan analisis geografis melalui gambargambar petanya. SIG dapat disajikan dalam 
bentuk aplikasi desktop maupun aplikasi berbasis web.

\section{METODOLOGI PENELITIAN}

Metode Pengumpulan Data yang akan dijadikan bahan dalan penelitian ini.

1. Observasi

Teknik pengumpulan data melalui pengamatan yang dilakukan terhadap objek yang akan diteliti dengan menggunakan pencatatan secara sistematis terhadap gejala-gejala yang berhubungan dengan masalah yang akan diteliti. Penulis melakukan observasi atau pengamatan langsung untuk mengumpulkan informasi dari Dinas Pariwisata Kabupaten Karo.

2. Wawancara

Yaitu metode pengumpulan data yang dilakukan dengan cara tanya jawab secara langsung dengan sekretaris umum Dinas Pariwisata Kabupaten Karo. Wawancara ini perlu dilakukan agar penulis mengetahui kelemahan yang terdapat pada sistem yang sedang berjalan di dinas tersebut.

3. Studi Pustaka

Studi pustaka yaitu penelitian yang dilakukan dengan cara membaca dan mempelajari buku-buku yang berhubungan dengan masalah yang akan diteliti sebagai tinjauan pustaka. Dalam penelitian ini, referensi yang digunakan berupa buku, jurnal serta penelusuran melalui internet.

\section{LANDASAN TEORI}

\subsection{Sistem Informasi}

Sistem informasi dapat didefinisikan sebagai suatu sistem di dalam suatu organisasi yang merupakan kombinasi dari orang-orang, fasilitas, teknologi, media, prosedur-prosedur dan pengendalian yang ditujukan untuk mendapatkan jalur komunikasi penting, memproses tipe transaksi rutin tertentu, memberi sinyal kepada manajemen dan yang lainnya terhadap kejadian-kejadian internal dan eksternal yang penting dan menyediakan suatu dasar informasi untuk pengambilan keputusan yang cerdik (Kadir, 2014).

\subsection{Sistem Informasi Geografis}

Sistem Informasi Geografis (SIG) merupakan suatu kumpulan yang terorganisir dari perangkat keras komputer, perangkat lunak, data geografi, dan personil yang dirancang secara efisien untuk memperoleh, menyimpan, memperbaharui, memanipulasi, menganalisis dan menampilkan semua bentuk informasi yang berreferensi geografi. SIG mampu membantu dalam pemecahan masalah dengan cara menampilkan data menggunakan cara yang mudah dipahami dan hasilnya mudah disebarluaskan (Kurniawan dan Setiaji, 2016).

\subsection{Google Maps}

Google Maps adalah jasa peta gratis dan online disediakan oleh Google yang dapat ditemukan di https://maps.google.com. Pada situs tersebut kita dapat melihat informasi geografis pada hampir semua wilayah di muka bumi. Layanan ini interaktif, karena di dalamnya peta dapat digeser sesuai keinginan pengguna, mengubah tingkat zoom, serta mengubah tampilan peta. Google maps juga menawarkan peta yang dapat diseret dan gambar setelit untuk seluruh dunia, serta menawarkan rute perjalanan (Minarni dan Yovi, 2015).

\subsection{Google Maps API}

Google Maps Application Programming Interface (API) merupakan suatu fitur aplikasi yang dikeluarkan oleh google untuk memfasilitasi pengguna yang ingin mengintegrasikan Google Maps ke dalam website masing-masing dengan menampilkan data point milik sendiri. Dengan menggunakan Google Maps API, Google Maps dapat di-embed pada website eksternal. Agar aplikasi Google Maps dapat muncul di website tertentu, diperlukan adanya API key. API key merupakan kode unik yang digenerasikan oleh google untuk suatu website tertentu, agar server Google Maps dapat mengenali.

Pada Google Maps API terdapat 4 jenis pilihan model peta yang disediakan oleh Google, diantaranya adalah:

1. Roadmap, untuk menampilkan peta biasa 2 dimensi.

2. Satellite, untuk menampilkan foto satelit.

3. Terrain, untuk menunjukkan relief fisik permukaan bumi dan menunjukkan seberapa tingginya suatu lokasi, contohnya akan menunjukkan gunung dan sungai.

4. Hybrid, akan menunjukkan foto satelit yang diatasnya tergambar pula apa yang tampil pada roadmap (jalan dan nama kota).

\section{HASIL DAN PEMBAHASAN}

\subsection{Analisis Kebutuhan Pengguna}

Kebutuhan pengguna meliputi apa saja yang dibutuhkan oleh pengguna pada sistem informasi geografis pariwisata berbasis web ini yaitu: 
1. Melihat tampilan peta dalam bentuk peta digital.

2. Mencari posisi suatu tempat pada peta.

3. Menemukan lokasi keberadaan pengguna.

4. Mendapatkan petunjuk arah menuju lokasi wisata.

5. Mendapatkan informasi objek wisata.

6. Melakukan Pengisian form buku tamu.

\subsection{Analisis Kebutuhan Admin}

Kebutuhan admin pada sistem ini meliputi apa yang dibutuhkan oleh admin pada sistem ini yaitu :

1. Melakukan proses login terhadap sistem.

2. Mengolah data obyek wisata.

3. Mengolah data fasilitas hotel, biro perjalanan dan rumah sakit.

4. Mengolah data buku tamu.

\subsection{Diagram Konteks}

Pada Diagram Konteks ini terdapat 2 entitas yaitu Pengunjung sebagai pengguna sistem dan admin sebagai pengelola sistem.

Secara garis besar diagram konteks

Sistem Informasi Geografis Pariwisata Kabupaten Karo Berbasis Web seperti pada Gambar 1.

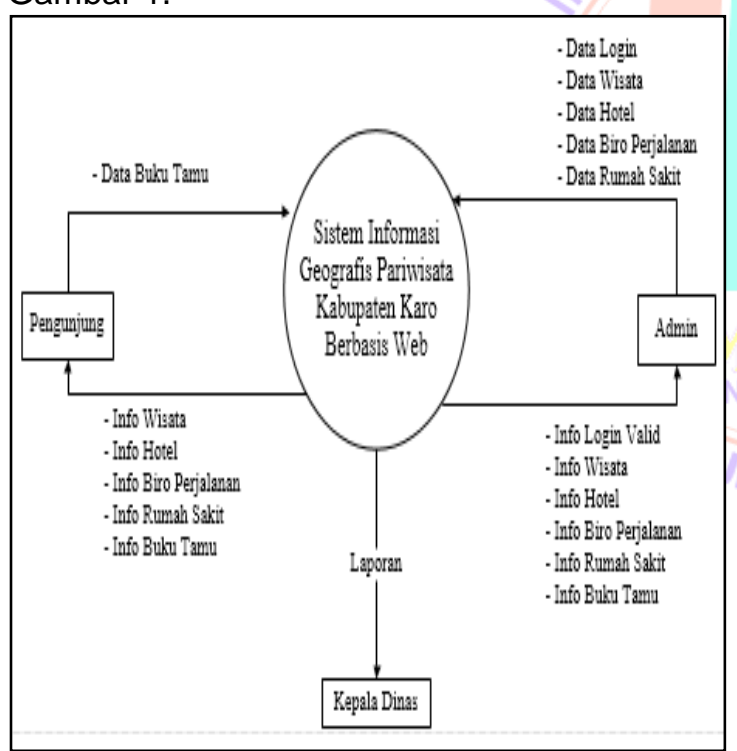

Gambar 1. Diagram Konteks Sistem Informasi Geografis Pariwisata Kabupaten Karo Karo Berbasis Web.

\subsection{Flowchart Menampilkan Map dari Google Maps}

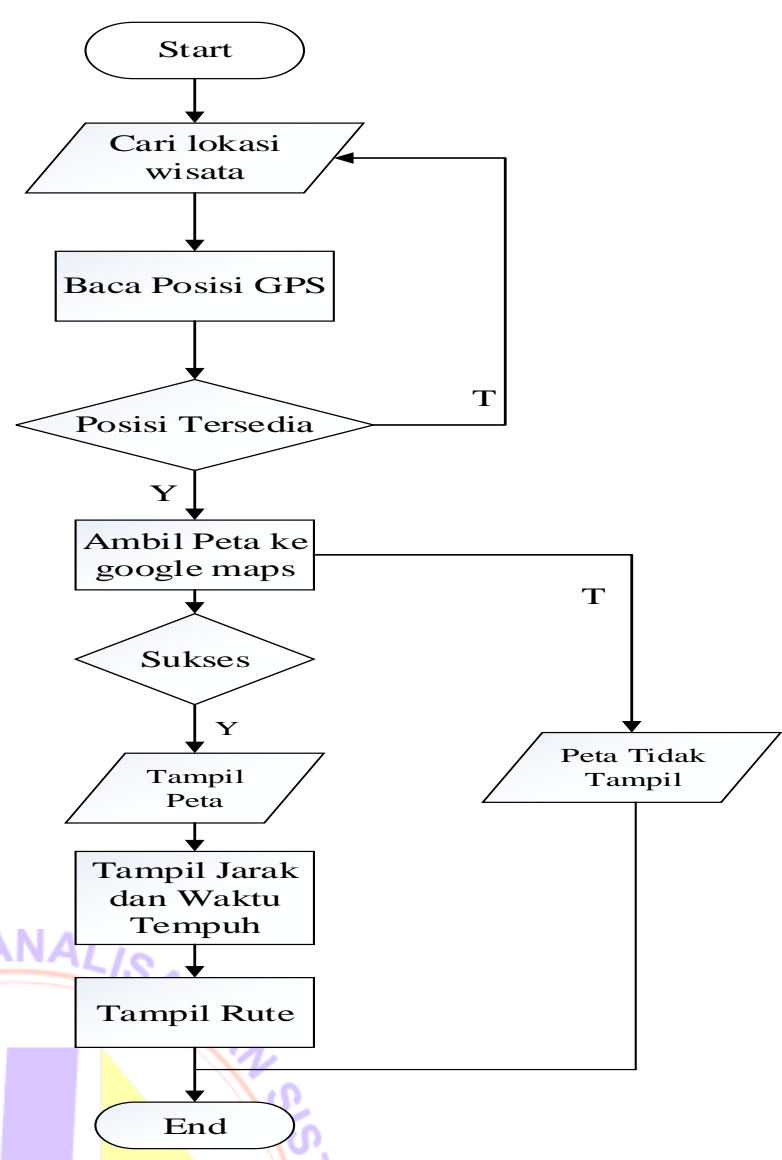

Gambar 2. Flowchart Menampilkan map dari Google Maps

Pada Gambar 2 pada saat proses menampilkan lokasi wisata dengan menggunakan fitur web yang di integrasikan ke Google Maps. Sistem terlebih dahulu mencari posisi awal pengguna atau perangkat. Apabila posisi awal ditemukan, selanjutnya proses pengambilan peta dari google maps. Jika pengambilan peta sukses, maka sistem dapat menampilkan jarak tempuh, dan estimasi perkiran waktu, serta menampilkan informasi rute yang akan dilalui.

\subsection{Implementasi Sistem}

Halaman Home merupakan halaman utama dari Website Sistem Informasi Geografis Pariwisata Kabupaten Karo Berbasis Web. Halaman ini berfungsi sebagai tempat untuk menampilkan informasi-informasi tentang Web ini. Adapun Tampilan Halaman Home, Seperti Pada Gambar 3. 


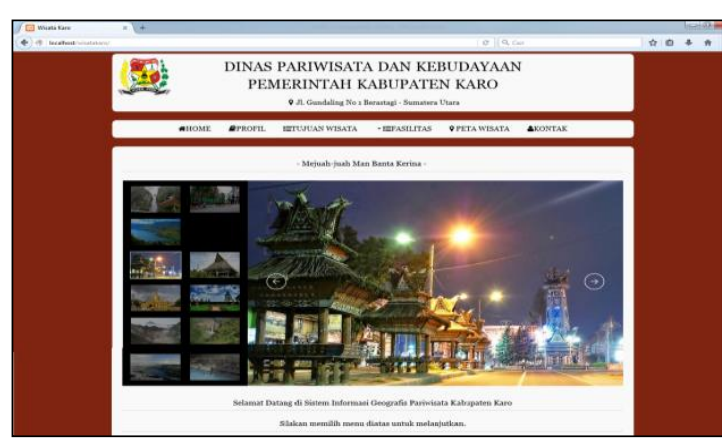

Gambar 3. Halaman Home

Halaman Profil merupakan halaman dari Website Sistem Informasi Geografis Pariwisata Kabupaten Karo Berbasis Web. Halaman ini berfungsi sebagai tempat untuk menampilkan Profil tentang Dinas Pariwisata Kabupaten Karo. Adapun Tampilan Halaman Profil, Seperti pada gambar 3.

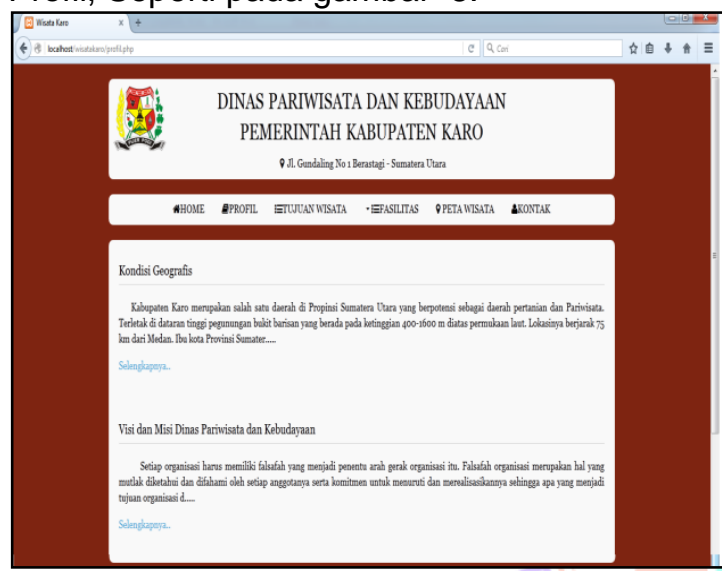

Gambar 4. Halaman Profil

Halaman Detail dan Lokasi Wisata merupakan link dari halaman tujuan wisata pada Website Sistem Informasi Geografis Pariwisata Kabupaten Karo Berbasis Web. Halaman ini berfungsi sebagai menampilkan detail informasi wisata, detail lokasi dan foto wisata. Adapun Tampilan Halaman Wisata, Seperti pada Gambar 5.

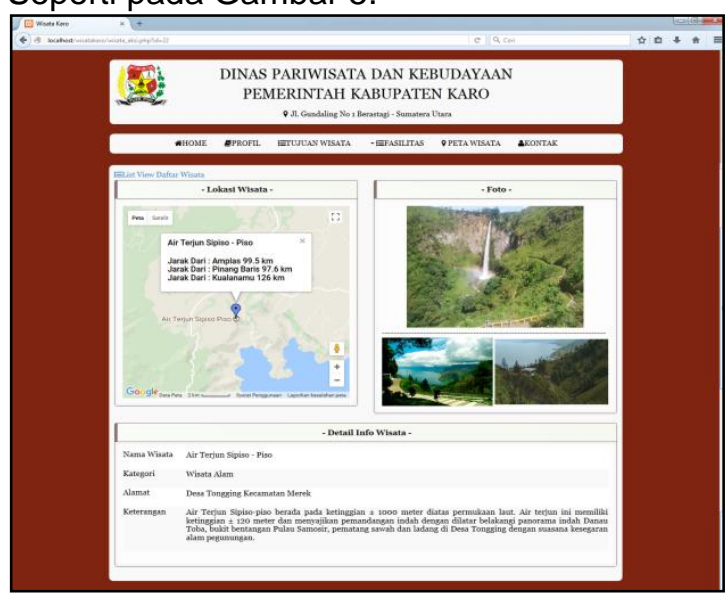

Gambar 5. Detail Lokasi Wisata
Halaman Peta Wisata merupakan halaman dari Website Sistem Informasi Geografis Pariwisata Kabupaten Karo Berbasis Web. Halaman ini berfungsi untuk melakukan pencarian lokasi wisata, menampilkan estimasi jarak dan waktu tempuh, serta jalur yang akan dilalui menuju lokasi wisata . Adapun Tampilan Halaman Peta Wisata, Seperti pada gambar 6 .

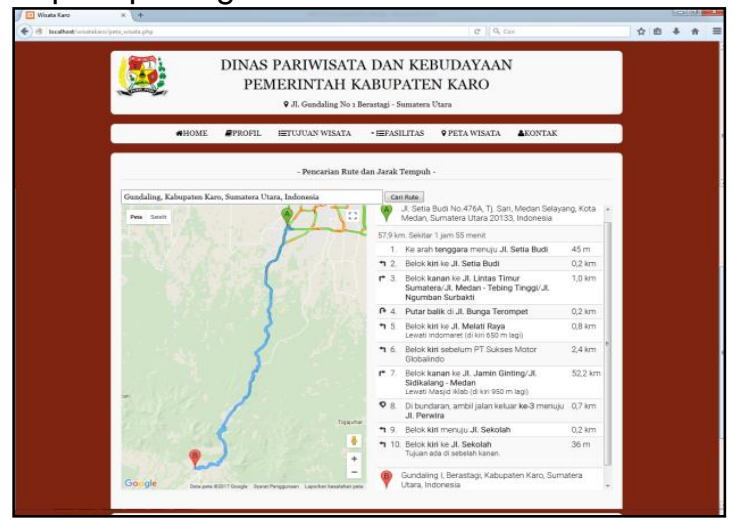

Gambar 6. Halaman Peta Wisata

Halaman utama admin merupakan tampilan utama untuk admin ketika telah sukses melakukan login. Tampilan halaman utama admin dapat dilihat pada gambar 7 .

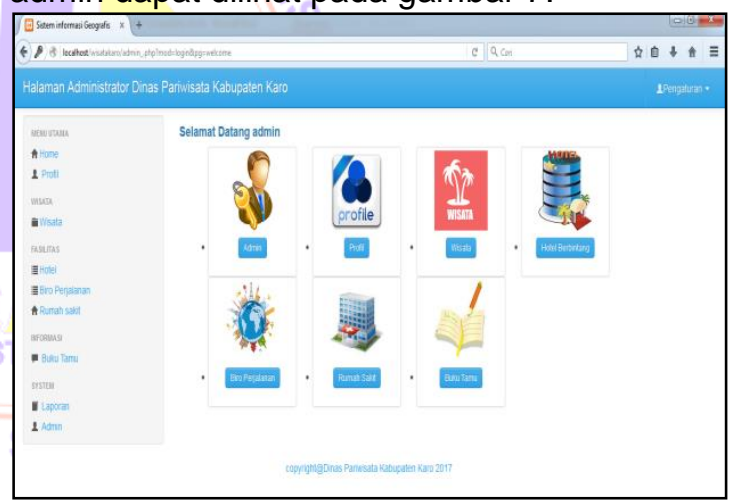

Gambar 7. Halaman Utama Admin

\section{KESIMPULAN}

Setelah penulis menyelesaikan penulisan ilmiah ini, maka penulis telah mendapatkan banyak ilmu pengetahuan yang baru, yang menambah wawasan serta pengalaman dalam bidang ilmu penelitian dan penulisan karya ilmiah. Dengan demikian penulis menyimpulkan bahwa :

1. Dengan adanya Sistem Informasi Geografis Pariwisata Kabupaten Karo Menggunakan Google Maps Berbasis Web yang dibangun ini, maka pihak Dinas Pariwisata dan Kebudayaan akan lebih mudah dan lebih akurat memberikan informasi tentang Pariwisata di Kabupaten Karo. 
2. Sistem informasi geografis ini dapat digunakan sebagai panduan mencari tempat wisata yang ada di Kabupaten Karo.

3. Sistem informasi geografis parwisata Kabupaten Karo, dapat menggantikan fasilitas informasi sebelumya yang menggunakan katalog, media cetak, brosur dan pamflet.

\section{DAFTAR PUSTAKA}

[1] Budiyanto, Eko. 2016. Sistem Informasi Geografis dengan Quantum GIS. Yogyakarta: Andi Offsite.

[2] Kadir, Abdul. 2009. Membuat Aplikasi Web dengan PHP + Database MySQL. Yogyakarta: Andi Offsite.

[3] Kadir, Abdul. 2014. Pengenalan Sistem Informasi Edisi Revisi. Yogyakarta: Andi Offsite.

[4] Kundyanirum, dkk. 2013. Sistem Informasi Geografis Pariwisata Kota Semarang. Semarang: Universitas Deponegoro.

[5] Kurniawan,Dwi Ely dan Setiaji,Eka Indra. 2016. Pemetaan Jalur Transportasi Bus Umum Kota Batam Menggunakan QuantumGIS dan Geoserver. Batam: Politeknik Negeri Batam.

[6] Lucyana, Resti. 2016. Sistem Informasi Geografis Pariwisata Untuk Pemetaan Pariwisata Kabupaten Pesisir Barat Berbasis Web. Lampung: Universitas Lampung.

[7] Minarni dan Yusdi,Yovi Febri. 2015. Sistem Informasi Geografi Pariwisata Kota Padang menggunakan Application Programming Interface (Api) Google Maps Berbasis Web. Padang: Institut Teknologi Padang.

[8] Nandi, 2008. Pariwisata dan Pengembangan Sumber Daya Manusia. GEA: Pendidikan Geografi.

[9] Utomo,Suprastyo. 2012. Pemanfaatan Mapserver Dalam Aplikasi Sistem Informasi Geografi Kota Bogor di Bidang Wisata dan Kuliner. Depok:Universitas Gunadarma. 